\title{
Pattern of Mortalities among Orthopaedic and Trauma Admissions in Irrua
}

\author{
E. O. Edomwonyi ${ }^{1 *}$, R. E. Enemudo², I. A. Okafor ${ }^{1}$ \\ ${ }^{1}$ Department of Orthopaedics and Traumatology, Irrua Specialist Teaching Hospital, Irrua, Nigeria \\ ${ }^{2}$ Department of Orthopaedics and Trauma, Delta State University Teaching Hospital, Oghara, Nigeria \\ Email: edwinedomwonyi@rocketmail.com
}

Received 15 June 2015; accepted 17 July 2015; published 20 July 2015

Copyright (C) 2015 by authors and Scientific Research Publishing Inc.

This work is licensed under the Creative Commons Attribution International License (CC BY). http://creativecommons.org/licenses/by/4.0/

CC) (†) Open Access

\begin{abstract}
Background: There are many reports from different parts of the world addressing different aspects of surgical mortality. However, none has been done in this centre as it relates to orthopaedics and trauma admissions. Such data are invaluable to health planning and epidemiological monitoring. Objective: To retrospectively review all mortalities arising from orthopaedics and trauma admission as they present to Irrua specialist Teaching Hospital (ISTH) Irrua from Jan 2005-Dec 2014. Method: Medical records of case mortalities among orthopaedic and trauma admissions over ten years (Jan 2005-Dec 2014) were retrospectively reviewed. Results: Over this period, 2129 admissions and 45 deaths were recorded, with an overall crude mortality rate of $2.11 \%$. No death was recorded among the paediatric age group. Thirty-four patients $(\mathbf{7 5 . 5 6 \% )}$ died from trauma (fracture) related diagnosis, majority of which were from head injury followed by infection $5(11.11 \%)$, tumours $4,(8.89 \%)$ and disc herniation $2(4.44 \%)$. Males were more affected $77.78 \%$ and median age at death was 44 years. Medical co-morbidities were found in $37.77 \%$ of the deceased patients. Conclusion: Patients with trauma related cases particularly head injuries, topped the list of mortalities. Young and middle aged adult males were most affected. Need for manpower development, investment in diagnostic and therapeutic facilities and preventive measures is emphasised.
\end{abstract}

Keywords

Pattern, Mortality, Orthopaedics and Trauma, Admissions

\section{Introduction}

In the year 1998/1999, there were 3.8 million acute admissions in hospitals throughout the United Kingdom and

${ }^{*}$ Corresponding author.

How to cite this paper: Edomwonyi, E.O., Enemudo, R.E. and Okafor, I.A. (2015) Pattern of Mortalities among Orthopaedic and Trauma Admissions in Irrua. Open Journal of Orthopedics, 5, 179-185. http://dx.doi.org/10.4236/ojo.2015.57024 
acute admissions for orthopaedics and trauma patients constituted $8 \%$ of these. [1] Centralised data of this nature are not available in Nigeria, but isolate and institution based studies [2] [3] from south-west Nigeria reveal that 5444 admissions into surgical wards over 5 years and 2418 orthopaedic and trauma admissions over 10 years respectively. The difference in number as well as nature of cases admitted may result from hospital policies on admissions, literacy levels of the societies, patronage of traditional bone-setters (TBS), and development of orthopaedic subspecialties and availability of facilities for admissions and treatment. These factors may also influence the outcome [4]-[7].

Orthopaedics ward admissions range from relatively healthy patients admitted for deformity corrections to those with simple fractures, polytrauma and chronic illnesses. These cover a whole spectrum of ages and added medical co-morbidities. Managing these illnesses or injuries could lead to surgical and medical complications with mortality being one of them. The pattern of mortality and morbidity reflects the burden of disease in a particular community. This pattern expresses geographic variations between communities and countries. Quoted figures for mortality in orthopaedics and trauma varies with lower figures in the advanced world [4]-[6].

Analysis of mortality and causes of death is an important step in identifying risk factors for death following trauma and disease. This is also useful in anticipating complications. In-hospital mortality has also been proposed an indicator of health care quality. It is useful for epidemiological monitoring, health planning and improves the quality of health care services in a nation. There are many reports from different parts of the world addressing different aspects of medical and surgical mortalities. There are few reports from our country. To the best of our knowledge, there is no report on pattern of mortalities among orthopaedics and trauma admissions from this centre, Irrua Specialist Teaching Hospital (ISTH) Irrua Edo State of Nigeria hence this review.

\section{Methods}

Between January 2005 and Dec. 31 $31^{\text {st }}$ 2014, we retrospectively studied all orthopaedics and trauma patients presenting to ISTH Irrua Edo State of Nigeria, who were admitted and subsequently died. Proforma was designed to document demographic details of the patients, primary diagnosis on admission, type of surgical intervention performed, duration between surgical intervention and death and duration of admission.

Death certificates, medical records and post-mortem examination findings were used to arrive at the possible causes of death of deceased patients. Study design was retrospective and descriptive. Cases with in complete records, patients that were brought in with soft tissue injuries only, were excluded from the study.

Ethical issues were duly observed in accordance with the institution's guidelines.

For the purpose of analysis, patient co-morbidity was defined as the presence of pre-existing medical conditions including, congestive cardiac failure, diabetes, hypertension, hypertensive heart disease, chronic obstructive pulmonary disease, previous cerbrovascular accident (stroke), chronic renal failure and liver disease.

Data collected was analysed using simple statistical method of percentages.

\section{Setting}

Irrua Specialist Teaching Hospital is a tertiary referral centre serving the orthopaedic and traumatic needs of a sub-urban population in the South-South Nigeria. It is a 375 bedded institution that receive referrals from neighbouring states. Admissions are mainly through the accident and emergency units, outpatient clinics and occasionally from the intensive care unit (ICU) and other hospital wards.

They consist of diverse groups of patients ranging deformity corrections to severely ill patients.

\section{Results}

During the 10 years period between Jan 2005-Dec. 2014, the total orthopaedics and trauma admission was 2129 patients. Adult admissions were 1822 (85.58\%) patients while paediatric admissions were 307 (14.42\%). Of the 1446 (67.92\%) male admissions, 201 were in the paediatric age group whereas of the 683 (32.08\%) female admissions, 106 were in the paediatric age group. The male to female ratio was 2.1:1.

Forty-five in-patient deaths were recorded over 10 years, giving a total crude mortality rate of $2.11 \%$. Male patient deaths 35 (77.78\%) constituted the majority, while 10 (22.22\%) female death were recorded, with M: F death ratio of 3.5:1.

Age ranged from 18 years to 90 years with 44 years as the median age. None of the deceased patient was in 
the paediatric age group. Table 1 show the age and sex distribution of the deceased patients.

Duration of admission: the length of stay ranged between 1 - 60 days with median of 6 days.

\subsection{Occupation}

Table 2 revealed the occupational distribution, more than half of the deceased patients were traders, farmers and civil servants.

\subsection{Primary Diagnoses on Admission}

The diagnosis in these patients fell generally under 4 categories: trauma 34, (75.56\%), infection 5, (11.11\%), tumor 4, (8.89\%) and disc herniation 2, (4.44\%). See Table 3.

No death was recorded among the paediatric age group.

Hypertension with hypertensive heart disease topped the list of medical co-morbid conditions found among orthopaedic and trauma admissions that eventually passed on. See Table 4.

Primary cause of death was different from primary diagnosis in many patients as shown in Table 5 . No record of post mortem examination was found. We were constrained to rely on the review of death certificates and medical records to determine primary/principal cause of death. This was a major constraint in this study.

Table 1. Age and sex distribution of patients.

\begin{tabular}{ccccccc}
\hline Age & Male & $\%$ & Female & $\%$ & Total & $\%$ \\
\hline $10-20$ yrs & O & O & 1 & 2.22 & 1 & 2.22 \\
$21-30$ & 7 & 15.56 & 1 & 2.22 & 8 & 17.78 \\
$31-40$ & 11 & $24-44$ & 1 & 2.22 & 12 & 26.67 \\
$41-50$ & 3 & 6.67 & 3 & 6.67 & 6 & 13.33 \\
$51-60$ & 5 & 11.11 & 0 & 0 & 5 & 11.11 \\
$61-70$ & 6 & 13.33 & 1 & 2.22 & 7 & 15.56 \\
$71-80$ & 2 & 4.44 & 1 & 2.22 & 3 & 6.67 \\
$80-90$ & 1 & 2.22 & 2 & 4.44 & 3 & 6.67 \\
Total & 35 & 77.78 & 10 & 22.22 & 45 & 100 \\
\hline
\end{tabular}

Table 2. Occupation of deceased in-patients.

\begin{tabular}{ccc}
\hline Occupation & Number & $\%$ \\
\hline Farming & 8 & 17.78 \\
Civil servants & 6 & 13.33 \\
Trading & 10 & 22.22 \\
Students & 5 & 11.11 \\
Artisans & 5 & 11.11 \\
Pensioners & 4 & 8.89 \\
Drivers & 4 & 8.89 \\
House wives & 2 & 4.44 \\
Not stated & 1 & 2.22 \\
Total & 45 & 100 \\
\hline
\end{tabular}


Table 3. Primary diagnoses in deceased patients.

\begin{tabular}{ccc}
\hline INJURY/DISEASE & NUMBER OF PATIENTS & $\%$ \\
\hline FRACTURE NECK OF FEMUR (pathologica) & 4 & 8.89 \\
HEAD INJURIES + LONG BONE FRACTURES & 12 & 26.67 \\
MULTIPLE LONG BONE FRACTURES & 9 & 20 \\
PELVIC FRACTURE + ABDOMINAL INJURIES & 3 & 6.67 \\
TIBIA FRACTURES ALONE/SINGLE & 2 & 4.44 \\
PELVIC FRACTURE + SPINAL CORD INJURY & 1 & 2.22 \\
CRUSH INJURIES & 3 & 6.67 \\
GANGRENE & 5 & 11.11 \\
OSTEOSARCOMA & 1 & 2.22 \\
MULTIPLE MYELOMA & 1 & 2.22 \\
DISC HERNIATION & 2 & 4.44 \\
METASTATIC PROSTATE CANCER & 2 & 4.44 \\
\hline
\end{tabular}

Table 4. Medicalco-morbid conditions in deceased patients.

\begin{tabular}{ccc}
\hline Disease & Frequency & $\%$ \\
\hline Diabetes mellitus & 4 & 8.89 \\
Chronic renal failure & 3 & 6.67 \\
Hypertension with hypertensive heart disease & 6 & 13.33 \\
Senile dementia & 2 & 4.44 \\
Chronic obstructive pulmonary Disease & 2 & 4.44 \\
Total & 17 & 37.78 \\
\hline
\end{tabular}

Table 5. Final event leading to death (primary cause of death).

\begin{tabular}{ccc}
\hline Primary cause of death & Frequency & $\%$ \\
Septicaemia & 11 & 24.44 \\
Anaemia & 4 & 6.89 \\
Renal failure & 3 & 13.33 \\
Head injury & 6 & 6.67 \\
Tumor & 3 & 6.67 \\
Pneumonia & 3 & 17.78 \\
DVT/Pulmonary embolism & 8 & 8.89 \\
Hypovolaemic shock & 4 & 4.44 \\
Diabetic ketoacidosis (DKA) & 8 & 8.89 \\
Multiple organ failure & 4 & 11.11 \\
Fat embolism & 5 & 4
\end{tabular}




\subsection{Surgical Intervention and Interval to Death}

Twenty one (46.67\%) of the deceased patients had surgical intervention before death while 24 (53.33\%) had none. The interval between intervention and death ranged from 1 - 60 days. Median 8 days.

The operations done for the patients included wound debridement, wound exploration, limb amputations and disarticulations for gangrene and tumours, tissue biopsies and external fixation of open fractures.

\section{Discussion}

Of patients who died in our hospital over the study period, nearly half of them were in third and fourth decades of life as shown in Table 1. Median age was 44 years. Orimolade et al. [3] from south west Nigeria reported a similar age at death of 45.7 yrs. These contrast with the pattern of death in the advanced world, where most mortalities in patients with fracturesis seen in the elderly, with an average age of 82.14 years [6]. Third and fourth decade of life represents a productive age in our society. The demise of these individuals at their primes would have negative impact on the social and economic well being of their families as well as the society.

Male dominance, with a sex ratio of 3.5:1 in mortality pattern was recorded. This may not be unrelated to the aetiology in most cases, which is trauma. Men are involved in higher risk activities. They are the bread winners in their families often times. They move from one place to the other transporting goods and services. This increases their vulnerability to road traffic accidents (RTA). RTA has been reported as the commonest cause of trauma in the developing world with male dominance [8]-[10].

Trauma topped the list of primary diagnoses made in deceased patients. Similar observations have been reported in other parts of the world such as India, England and Ethiopia [4]-[7], majority of our admissions were injury related.

Trauma, particularly that occurring from RTA has become major health problems throughout the world and especially in low and middle income countries [11] [12]. In Nigeria, trauma is reported as the commonest cause of death among surgical admissions and in the accident and emergency [13], as well as surgical wards [2]. No death was recorded among the paediatric age group in our study. However, this contrast with findings from Owo [14] as well as Ife [15], both in Western part of Nigeria, were not only deaths were recorded but trauma was quoted as being responsible for the highest incidence of surgical admissions and deaths among the paediatric group. As children, critical decisions are often taken on their behalf by parents or guardians. This would impact on when and where they obtain care. This also showed in the wide gap in the number of paediatric and adult admissions.

Tumours and infections also featured in our series. Incidence of Infections was higher than tumours as clinical causes of mortality. Tan H. B. [6] et al. reported tumors as the leading cause of death in those $<64$ yrs of age while Bhattacharyya et al. [5] reported trauma, tumor and infection as the leading cause of death in a series in Boston.

Prevalence of medical co-morbidity was seen in $37.78 \%$ of deceased patients. Orimolade et al. [3] recorded $39.3 \%$ in a similar study. These medical conditions reduces a patient's systemic reserves, which may lead to peri-operative and postoperative complications. One of these complications is mortality. Moran CG et al. [16] also reported a significantly increased mortality after hip fracture among patients with acute medical co-morbidities. This further highlight the need for collaboration with other specialists in the management of orthopaedic and trauma patients.

Associated head injury accounted for $26.67 \%$ of primary diagnosis and $13.33 \%$ of the primary cause of death as shown in Table 5. Other authors [3] [8] [10] also reported similar findings. Nast-kolb et al. [17] reported that severe brain injury was the leading cause of death in young patients with multiple injuries admitted to intensive care unit (ICU). Diagnostic and therapeutic facilities in the neurosurgery unit of our hospitals can be better. Channelling resources towards manpower development as well as provision of these life saving facilities would reduce the incidence of deaths among head injured patients.

Thrombo-embolism was identified as primary cause of death in $17.78 \%$ while fat embolism in $11.11 \%$ of cases as reflected in Table 5. Pulmonary embolism appears not be as rare as it was said to be in the past among Nigerians [18]. Ayoade et al. [2] reported a figure as high as $14.3 \%$ in a similar study done in Sagamu in Western part of Nigeria. Rising awareness of this condition, vulnerability of orthopaedic and trauma patients, changing life style of Nigerians, poor attitude to routine and regular medical check up among the middle aged class may be responsible for its relatively high frequency among the deceased orthopaedic and trauma patients in this 
series.

Septicaemia ranked the highest as the primary cause of death among deceased in this study. Reports [6] from developed nations reveal lower figures. Delay in obtaining consent for amputations in wet and gas gangrene, late presentations, high patronage of traditional bone-setters, poverty and lack of efficient and effective health insurance system in our society, may explain this gap.

Farmers, civil servants and traders constitute more than $50 \%$ of the deceased patients. This has a negative impact on food sustainability, business as well national productivity.

None of our deceased patients had post-mortem examination. It is either some had post mortem examination, but records were missing or they were never done in the first place. Orimolade et al. [3] recorded post mortem examination figure as low as $20 \%$ in a similar study. This significantly undermines our capacity to access information from post mortem examinations and records. This is not surprising because it has been reported that in most African countries, there are considerable shortcomings in their sources which at times, less than $10 \%$ of service injuries or trauma related deaths are recorded in official data [19] [20]. Cost of post mortem examination, as relatives are expected to pay for this procedure, cultural belief about reincarnation with fears that the deceased may return disabled, failure to give consent, religious demand on immediate burial of the dead are factors that may be responsible for this paucity of post-mortem records in this study.

Autopsy remains the best way of establishing the cause of death. Not having the benefit of post mortem examination records was a major limitation in this study, as we had to rely on medical records as well as death certificates in determining primary/principal cause of death. Post-mortem should be made free of charge, enact and enforce legislation to address the socio-cultural impediments, would go a long way to re-orienting our people to this important investigative tool.

\section{Conclusion}

Young and productive adult males topped the list of mortalities recorded. Trauma related diagnosis, particularly head injuries related cases accounted for the majority of deaths among orthopaedic and trauma in-patients. Road safety regulations should be strengthened and enforced. Manpower should be developed; vital infrastructures such as diagnostic and therapeutic facilities should be provided and upgraded on a regular basis. This would go a long way in reducing this burden.

\section{Acknowledgements}

We appreciate Mr Ijie, the head as well as staff of health information department of ISTH Irrua for their co-operation in carrying out this study.

\section{Conflict of Interest}

None was declared.

\section{Source of Funding}

Funds were not received from any institution, organisation or corporate body for this work.

\section{References}

[1] Department of Health. Hospital In-Patient Data Based on Hospital Episode Statistics (HES). http://www.doh.gov.uk/hes/

[2] Ayoade, B.A., Thanni, L.O. and Shonoiki-Oladipupo, O. (2013) Mortality Pattern in Surgical Wards of a University Teaching Hospital in South West Nigeria: A Review. World Journal of Surgery, 37, 504-509. http://dx.doi.org/10.1007/s00268-012-1877-5

[3] Orimolade, E.A., Akinyoola, A.L., Ikem, I.C., Oginni, L.M., Olasinde, A.A. and Esan, O. (2011) Mortality among Orthopaedic and Traumatology Admissions: A Ten Year Review. Nigerian Journal of Orthopaedics and Trauma, 10, 4752.

[4] Ahmed, E. and Chaka, T. (2005) The Pattern of Orthopaedic Admissions in Tikur Anbessa University Hospital, Addis Ababa. Ethiopian Medical Journal, 43, 85-91.

[5] Bhattacharyya, T., Lorio, R. and Healy, W.L. (2002) Rate of and Risk Factors for Acute Inpatient Mortality after Or- 
thopaedic Surgery. Journal of Bone \& Joint Surgery, 84, 562-572.

[6] Tan, H.B., McDonald, D.A., Matthews, S.J. and Giannoudis, P.V. (2004) Incidence and Causes of Mortality Following Acute Orthopaedic and Trauma Admissions. Annals of the Royal College of Surgeons of England, 86, 156-160. http://dx.doi.org/10.1308/003588404323043256

[7] Elias, A. and Tezera, C. (2005) Orthopaedic and Major Limb Trauma at the Tikur Anbessa University Hospital, Addis Ababa Ethiopia. East and Central African Journal of Surgery, 10, 43-50.

[8] Thanni, L.O. and Kehinde, O.A. (2006) Trauma of a Nigerian Teaching Hospital Pattern and Documentation of Presentation. African Health Sciences, 6, 104-107.

[9] Adeolu, A.A., Malomo, A.O., Shokunbi, M.T., Komolafe, E.O. and Abiona, T.C. (2005) Etiology of Head Injuries in South-Western Nigeria. A Public Health Perspective. The Internet Journal of Epidemiology, 2.

[10] Adesukanmi, A.R., Oginni, L.M., Oyelami, O.A. and Badru, O.S. (2000) Road Traffic Accidents in African Children: Assessment of Severity Using the Injury Severity Score (ISS). Injury, 31, 225. http://dx.doi.org/10.1016/S0020-1383(99)00236-3

[11] Mock, C. Quansah, R., Krishnan, R., Arreola-Rissa, C. and Rivarra, F. (2004) Strengthening the Prevention and Care of Injuries Worldwide. The Lancet, 363, 2172-2179. http://dx.doi.org/10.1016/S0140-6736(04)16510-0

[12] Krug, E.G., Sharma, G.K. and Lozano, R. (2000) The Global Burden of Injuries. American Journal of Public Health, 90, 523-526. http://dx.doi.org/10.2105/AJPH.90.4.523

[13] Ekere, A.U., Yellowe, B.E. and Umunne, S. (2005) Mortality Patterns in the Accident and Emergency Department of an Urban Hospital in Nigeria. Nigerian Journal of Clinical Practice, 8, 14-18.

[14] Olasinde, A., Oluwadiya, K., Akinkuolie, A. and Oginni, L. (2005) Paediatric Surgical Admissions in a Tertiary Hospital in Western Nigeria. The Internet Journal of Paediatrics and Neonatology, $\mathbf{5}$.

[15] Thanni, L.O., Shonubi, A.M. and Akiode, O.A. (2005) Retrospective Audit of Paediatric Surgical Admissions in a Sub-Urban Tertiary Hospital. West African Journal of Medicine, 24, 10-12.

[16] Moran, C.G., Wenn, R.T., Sikand, M. and Taylor, A.M. (2005) Early Mortality after Hip Fracture: Is Delay before Surgery Important? Journal of Bone \& Joint Surgery, 87, 483-489.

[17] Nast-kolb, D., Aufmkolk, M., Rucholtz, S., Obertacke, V. and Waydhas, C. (2001) Multiple Organ Failure Still a Major Cause of Morbidiity but Not Mortality in Blunt Multiple Trauma. The Journal of Trauma, 51, 835-841. http://dx.doi.org/10.1097/00005373-200111000-00003

[18] Sotunbi, P.T., Idowu, A.T., Akang, E.E. and Aken’Ova, Y.A. (2006) Prevalence of Venous Thromboembolism of Post Mortem in an African Population: A Cause for Concern. African Journal of Medicine and Medical Sciences, 35, 345348.

[19] London, J., Mock, C.N., Abantanga, E.A., Quansah, R.E. and Boateng, K.A. (2002) Using Mortuary Statistics in the Development of an Injury Surveillance System in Ghana. Bulletin of the World Health Organization, 80, 357-364.

[20] Salifu, M. and Mock, C.N. (1998) Pedestrian Injuries in Kumasi: Results of an Epidemiologic Survey. The Ghana Engineer, 18, 23-27. 